\title{
FATES OF ERODED SOIL ORGANIC CARBON: MISSISSIPPI BASIN CASE STUDY
}

\author{
S. V. Smith,,${ }^{1,5}$ R. O. Sleezer, ${ }^{2}$ W. H. Renwick, ${ }^{3}$ And R. W. Buddemeier ${ }^{4}$ \\ ${ }^{1}$ Departamento de Ecología, Centro de Investigación Científica y de Educación Superior de Ensenada, Ensenada, \\ Baja California 22860, Mexico \\ ${ }^{2}$ Earth Science Department, Emporia State University, Emporia, Kansas 66801 USA \\ ${ }^{3}$ Department of Geography, Miami University, Oxford, Ohio 45056 USA \\ ${ }^{4}$ Kansas Geological Survey, University of Kansas, Lawrence, Kansas 66047 USA
}

\begin{abstract}
We have developed a mass balance analysis of organic carbon (OC) across the five major river subsystems of the Mississippi (MS) Basin (an area of $3.2 \times 10^{6} \mathrm{~km}^{2}$ ). This largely agricultural landscape undergoes a bulk soil erosion rate of $\sim 480 \mathrm{t} \cdot \mathrm{km}^{-2} \cdot \mathrm{yr}^{-1}$ $\left(\sim 1500 \times 10^{6} \mathrm{t} / \mathrm{yr}\right.$, across the MS Basin), and a soil organic carbon (SOC) erosion rate of $\sim 7 \mathrm{t} \cdot \mathrm{km}^{-2} \cdot \mathrm{yr}^{-1}\left(\sim 22 \times 10^{6} \mathrm{t} / \mathrm{yr}\right)$. Erosion translocates upland SOC to alluvial deposits, water impoundments, and the ocean. Soil erosion is generally considered to be a net source of $\mathrm{CO}_{2}$ release to the atmosphere in global budgets. However, our results indicate that SOC erosion and relocation of soil apparently can reduce the net SOC oxidation rate of the original upland SOC while promoting net replacement of eroded SOC in upland soils that were eroded. Soil erosion at the MS Basin scale is, therefore, a net $\mathrm{CO}_{2}$ sink rather than a source.
\end{abstract}

Key words: $\mathrm{CO}_{2}$; erosion; Mississippi Basin; regional budget; soil fertility; soil organic carbon.

\section{INTRODUCTION}

We analyze the role of soil and soil erosion in the carbon cycle by quantitatively assessing soil erosion, translocation, redeposition, oxidation, and $\mathrm{CO}_{2}$ sequestration across the five major river subsystems in the Mississippi Basin (Fig. 1). These were analyzed by aggregating soil composition and erosion data at the level of USGS HUC8 cataloging units (a total of 833 such units, with an average area of about $4000 \mathrm{~km}^{2}$; see Appendix). While there are environmental, agricultural, and socioeconomic reasons to study soil erosion and to minimize anthropogenic enhancement of erosion, we focus here on erosion in the context of organic carbon (OC) mass balance.

Fig. 1a shows a budgetary framework for tracking eroded soil and associated soil organic carbon (SOC) from upland soils, through various transport pathways and depositional compartments within a subsystem of the Mississippi Basin, to the eventual removal from that subsystem of some fraction of the eroded SOC via river transport. Solid arrows represent lateral relocation of soil and SOC after they are mobilized during erosion. Dotted arrows illustrate possible sites of OC oxidation ("Ox?") and $\mathrm{CO}_{2}$ sequestration into OC ("Seq?"). Of particular interest is the role of soil erosion in the balance between Ox and Seq as SOC moves through the system.

Quantifying global SOC and anthropogenically induced changes in SOC are conceptually simple but op-

Manuscript received 18 January 2005; revised 18 April 2005; accepted 27 April 2005. Corresponding Editor: B. A. Hungate.

${ }^{5}$ E-mail: svsmith@hawaii.edu erationally difficult. Current estimates for the mass of SOC in the upper $100 \mathrm{~cm}$ of soil are 1500 to $1600 \mathrm{Gt}$ (metric ton $=\mathrm{t}=1 \mathrm{Mg}$ ) (e.g., Bohn 1982, Eswaren et al. 1993, Jobbagy and Jackson 2000), but there are serious uncertainties in these estimates: (1) spatial variability in SOC within landscapes and mapping units (Jobbagy and Jackson 2000); (2) uncertainties about the temporal effects of land-use practices (tillage methods, cropping practices, fertilizer application rates, etc.) on in situ balances between SOC oxidation, $\mathrm{CO}_{2}$ sequestration into SOC, erosion, and the fates of eroded and relocated SOC (Rosenzweig and Hillel 2000, Amundson 2001, Post et al. 2001, Swift 2001, Lal 2003, Liu et al. 2003, Lal et al. 2004); and (3) the inadequacy of remote sensing to meet the needs for increased accuracy.

Lal $(1995,2003,2004)$ indicates that a significant portion of eroded SOC is exposed to greater oxidation rates during and after erosion. He attributes this increased oxidation largely to the breakdown of aggregates, exposing more SOC to the atmosphere and thus reducing OC of eroded soil by $\geq 20 \%$. This assumption has been widely used in models of the carbon cycle, but regionally integrated evidence for erosion-associated oxidation consists primarily of the observation that little eroded $\mathrm{C}$ is exported to the ocean (e.g., Schlesinger 1995).

Fluvial geomorphologists recognize that there can be a long (millennial) delay between upland erosion of bulk materials and discharge of those materials from large river basins to the ocean (e.g., Meade et al. 1990, Dearing and Jones 2003). Even at scales of smaller 


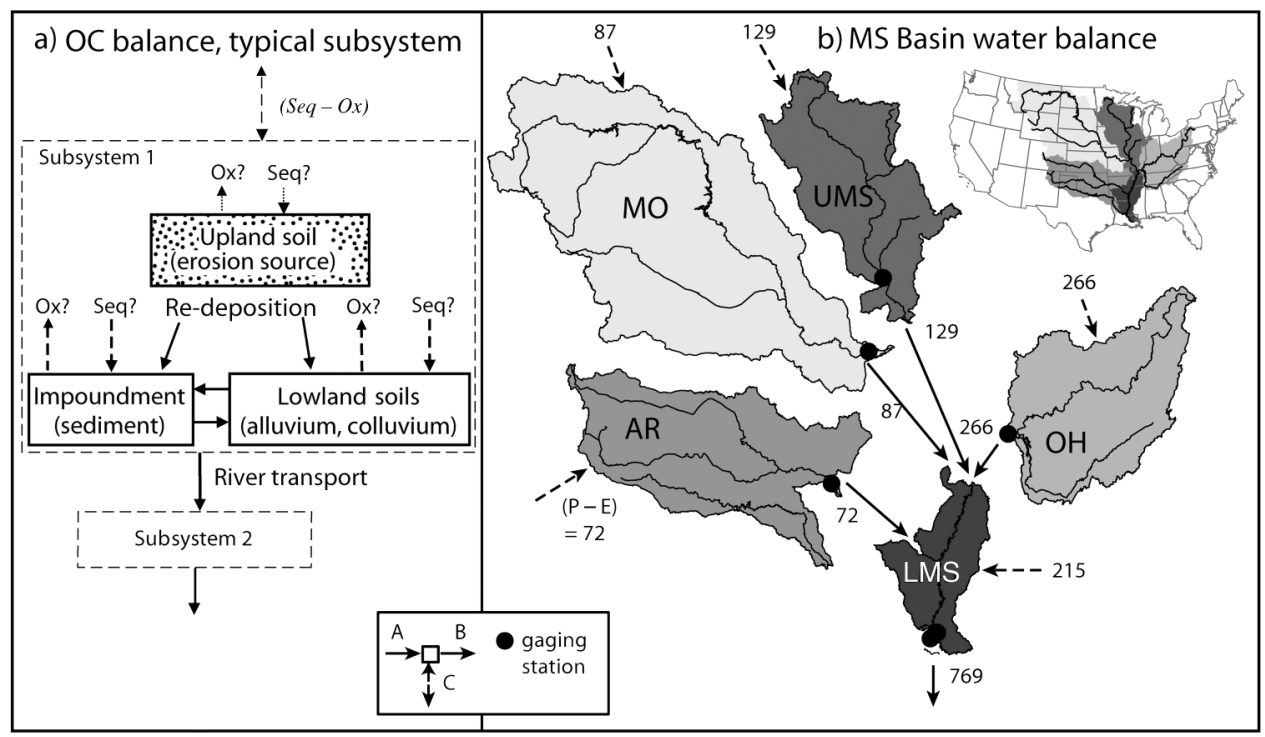

c) MS Basin water, sediment, and OC balances

\begin{tabular}{|c|c|c|c|c|c|c|c|}
\hline & & AR & MO & UMS & $\mathrm{OH}$ & LMS & MS Basin \\
\hline \multicolumn{8}{|c|}{ A. $\stackrel{\text { A }}{\rightarrow} \square$ Direct estimate of input or mobilization } \\
\hline 1. & water (river influx) & & & & & 554 & \\
\hline $2 \mathrm{a}$. & sediment (erosion) & 184 & 570 & 313 & 345 & 111 & 1523 \\
\hline $2 b$. & sediment (river influx) & & & & & 146 & \\
\hline $3 a$. & OC (erosion) & 1.7 & 8.4 & 7.3 & 5.2 & 1.1 & 23.7 \\
\hline $3 b$. & OC (river influx) & & & & & 3.9 & \\
\hline \multicolumn{8}{|c|}{ B. $\quad \stackrel{\text { B }}{\rightarrow}$ Direct estimate of output or retention } \\
\hline 1. & water (river efflux) & 72 & 87 & 129 & 266 & 769 & 769 \\
\hline 2. & sediment (river efflux) & 8 & 78 & 26 & 34 & 161 & 161 \\
\hline $3 a$. & OC (river efflux) & 0.4 & 0.9 & 1.2 & 1.4 & 4.8 & 4.8 \\
\hline $3 \mathrm{~b}$. & OC (redeposition) & 1.6 & 7.2 & 6.7 & 4.7 & 1.1 & 21.3 \\
\hline \multicolumn{8}{|c|}{ C. $\square \stackrel{C}{\leftrightarrow}$ Inferred + or - to balance budget } \\
\hline 1. & water $(P-E)$ & +72 & +87 & +129 & +266 & +215 & +769 \\
\hline 2. & sediment (redeposition) & -176 & -492 & -287 & 311 & -96 & -1362 \\
\hline 3. & $O C(\operatorname{Seq}-O x)$ & +0.3 & -0.3 & +0.6 & +0.9 & +0.9 & +2.4 \\
\hline
\end{tabular}

FIG. 1. (a) Conceptual diagram illustrating upland soils as erosional sources delivering materials to alluvial soils, water body sediments, and river transport. Oxidation (Ox?) and $\mathrm{CO}_{2}$ sequestration (Seq?) can accompany each step in the erosion, transportation, and deposition sequence. (b) Location map showing the five major subsystems of the Mississippi Basin, and an "exploded map" that illustrates fluxes within and between the subsystems. Arrows and associated numbers show the water budget from lines A1, B1, and C1 of Fig. 1c; the LMS influx is the sum of the efflux from the other subbasins. River gaging stations (Appendix Table A1) are shown as black circles on the exploded map. (c) Budgets of water, bulk sediment, and organic carbon (OC) fluxes within and between the subsystems. Direct estimates of inputs, outputs, and mobilization or retention within the subsystems are based on independently available estimates. Inferred values are fluxes that are required to close the budgets: for water, river fluxes between the subsystems must be balanced by $(\mathrm{P}-\mathrm{E})$; for sediments, the difference between sediment erosion and river flux is assumed to be retained (redeposited) within the subsystem. The OC contents of eroded soil, deposited sediment, and river fluxes are all known, so the net of (Seq - Ox) is required to balance the organic carbon budget within each subsystem. Water fluxes are in $10^{9} \mathrm{~m}^{3} / \mathrm{yr}$; sediment and OC fluxes are in $10^{6} \mathrm{t} / \mathrm{yr}$. Entries in part $\mathrm{C}$ of the table are italicized to emphasize that they are inferred to balance the budget, rather than being directly estimated.

individual catchments, this delay can be considerable (e.g., Trimble 1983, Church and Slaymaker 1989, Phillips 1991). The OC fraction of bulk erosion products would experience a similar delay. Raymond and Bauer (2001) estimated that OC transported in American rivers varies in age between about 700 and 5000 years.
It should be noted, however, that the OC age range reflects the combination of the age of OC reaching the rivers and the time for that $\mathrm{OC}$ to be transported through the river systems.

The extent to which increased SOC oxidation occurs as a direct result of erosion has not been reliably quan- 
TABLE 1. Characteristics of the MS Basin and its subsystems.

\begin{tabular}{lcccccc}
\hline \hline Subsystem & $\begin{array}{c}\text { Area } \\
\left(10^{6} \mathrm{~km}^{2}\right)\end{array}$ & $\begin{array}{c}\text { Mean } \\
\text { elevation } \\
(\mathrm{m})\end{array}$ & $\begin{array}{c}\text { (Maximum } \\
- \text { minimum) } \\
\text { elevation }(\mathrm{m})\end{array}$ & $\begin{array}{c}\text { Mean annual } \\
\text { temperature } \\
\left({ }^{\circ} \mathrm{C}\right)\end{array}$ & $\begin{array}{c}\text { Mean annual } \\
\text { precipitation } \\
(\mathrm{cm})\end{array}$ & $\begin{array}{c}\text { Cropland } \\
(\%)\end{array}$ \\
\hline AR & 0.642 & 706 & 4246 & 13.7 & 81 & 38 \\
MO & $1.350 \dagger$ & 999 & 4158 & 7.6 & 53 & 41 \\
UMS & 0.492 & 298 & 536 & 8.2 & 86 & 65 \\
OH & 0.528 & 345 & 1890 & 11.9 & 119 & 38 \\
LMS & 0.210 & 81 & 751 & 16.7 & 140 & 47 \\
MS Basin & 3.222 & 664 & 4282 & 10.2 & 81 & 44 \\
\hline
\end{tabular}

Notes: Abbreviations used are AR, Arkansas-Red; MO, Missouri; UMS, upper Mississippi; $\mathrm{OH}$, Ohio-Tennessee; LMS, lower Mississippi; MS, Mississippi.

$\dagger$ Includes $\sim 30000 \mathrm{~km}^{2}$ in Canada.

tified. A study of $\mathrm{CO}_{2}$ fluxes from soils in Ohio showed the highest SOC contents in depositional-phase soils, and no statistically significant differences in $\mathrm{CO}_{2}$ fluxes between soils in depositional phases and those characterized as in severe, moderate, or slight erosion phases (Bajracharya et al. 2000). Pedologists and soil geomorphologists have recognized that soils in depositional slope positions (toe slopes, floodplains, etc.) generally have higher SOC contents than soils in erosional slope positions (sloping summit, shoulder, backslope, etc.) (Kleiss 1970, Martel and Paul 1974, Aguilar and Heil 1988), although variations have been noted (Yonker et al. 1988, Brubaker et al. 1993). The spatial pattern of higher SOC contents in depositional slope positions is probably some function of the deposition of organic-rich topsoil, with higher moisture contents supporting more lush vegetation (i.e., greater biomass inputs), and the fact that soils above some optimum moisture content have diminished oxidation rates (Liu et al. 2003).

SOC can accumulate photosynthetically back into the soil profile after erosion. Modeling studies by Stallard (1998), Harden et al. (1999), and Liu et al. (2003) have pointed out the potential importance of "dynamic replacement" of SOC in eroded soil profiles. Van Oost et al. (2004) observed that erosion and subsequent dynamic replacement can lead to net $\mathrm{CO}_{2}$ sequestration rates of the same magnitude as no-till agriculture, an increasingly used conservation practice in the United States and elsewhere (e.g., Uri 2001).

This paper is an examination, at a regional scale, of the fates of SOC from upland soil erosion through redeposition or river export. Erosion moves bulk soil and SOC from one location to another. We account for the translocated bulk materials in order to determine how much the OC content of the bulk soil changes as it is relocated. This permits estimation of, or inference about, organic matter (OM) oxidation and production rates and how they are likely to affect $\mathrm{C}$ cycling at regional and global scales.

\section{STUdy REgION}

We have extended our original sediment and OC budgets for the conterminous United States (Smith et al.
2001) to a more detailed mass balance analysis for five major river subsystems that together comprise the 3.2 $\times 10^{6} \mathrm{~km}^{2}$ Mississippi (MS) Basin (Fig. 1b). The subsystems are approximately equal to USGS Water Resources Hydrological (HUC2) Units 05-06 (Ohio, Tennessee: $\mathrm{OH}$ ), 07 (Upper MS: UMS), 10 (Missouri: MO), 11 (Arkansas, Red: AR), and 08 (lower MS: LMS) (see Appendix).

The MS Basin constitutes $\sim 40 \%$ of the conterminous United States and spans a wide range of physiographic and climatic conditions. Regional catchment relief (maximum-minimum elevation) and area are considered to be primary variables controlling river sediment yield (Milliman and Syvitski 1992, Syvitski and Moorehead 1999). Jenny (1941) and subsequent authors (summary in Amundson 2001) have recognized the importance of mean annual temperature and precipitation as regional factors influencing the spatial distribution of SOC. Because of their potential importance in bulk soil erosion, sediment yield, and SOC distribution, these physiographic and climatic variables are summarized in Table 1 (see details in Appendix).

Soils within the MS Basin provide a reasonable cross section of soil orders found within temperate latitudes. Mollisols and Alfisols are the dominant soil orders, especially within the Great Plains and Midwest; however, significant areas of Ultisols, Entisols, Inceptisols, Histosols, Vertisols, Aridisols, and Spodosols are present within the MS Basin (Soil Survey Staff 1999).

The MS Basin accounts for $70 \%$ of U.S. cropland. About $60 \%$ of the cattle and $90 \%$ of the hogs in the United States are found in the basin. The combination of agricultural, physiographic, and climatic variables are ideal for examining the OC budget of this large agricultural region, and its size and diversity make it likely that conclusions about the MS Basin are applicable elsewhere.

The hydrology of the MS Basin is conveniently considered in terms of a simple "plumbing diagram" that treats the subsystems as storage compartments (Fig. 1b). Landscape processes occur within each compartment (Fig. 1a), and river flow is the common drain that transfers materials from the subsystems and eventually to the ocean. The Missouri (MO) converges with the 
upper MS (UMS) near St. Louis, Missouri. The OhioTennessee $(\mathrm{OH})$ and the UMS converge about $200 \mathrm{~km}$ southeast of St. Louis; below that point the MS is identified as the lower MS (LMS). The Arkansas and the Red River systems flow separately into the western side of the LMS subsystem about 400 and $700 \mathrm{~km}$ south, respectively, of the $\mathrm{OH}$ inflow. Because data are scanty for the Red River system (the smaller of these two), these have been aggregated into a single subsystem (AR).

\section{Materials and Methods}

This section summarizes the materials and methods used in our analyses. More detailed descriptions are given in the Appendix.

\section{River-borne fluxes}

River fluxes of water, total suspended sediment (TSS), and dissolved and particulate OC (DOC, POC) at the gaging stations shown on Fig. $1 \mathrm{~b}$ were calculated and scaled to the total subsystem areas.

\section{Erosion}

The methodology for erosion estimation is discussed in Smith et al. (2001) and in the Appendix. Data are aggregated at the scale of the USGS 8-digit hydrologic mapping units. There are 833 HUC 8 units across the MS Basin (after removal of ones that are water or local drainages near the mouth of the MS River). The average size of the remaining HUC8s is $\sim 4000 \mathrm{~km}^{2}$.

In the present mass balance analysis, water, bulk sediment, and OC budgets are linked. River flow through the system establishes the excess of precipitation over evaporation $(P-E)$. Independent estimates of $(P-E)$ are used to validate the water budget. Bulk soil is detached and transported by slope erosion processes. Some of this detached soil reaches channels through which it is transported as suspended sediment into larger perennial streams. We assume that the remainder is redeposited somewhere within the subsystem of origin. In Smith et al. (2001) we established that depositional sites within the system (large and small water impoundments, alluvial sediments, etc.) readily have the capacity to receive the estimated amount of eroded soil, without the need to constrain the budget with a very uncertain (statistically noisy) direct estimate of redeposition from impoundment sedimentation rates. We follow that same approach here.

OC from eroded soil also moves through the stream network. OC that does not exit each subsystem via rivers either locally accumulates in depositional sites or might be oxidized. The percent OC relative to bulk materials in the eroding soils, in alluvial and impoundment depositional sites, and in river transport is estimated, so that OC fluxes can be scaled to bulk sediment fluxes. Scaling the OC mass to bulk sediment mass leaves a residual amount of $\mathrm{OC}$ required to balance the OC budget. This residual is attributed to the difference between oxidation and sequestration processes linking SOC to atmospheric $\mathrm{CO}_{2}$ (Fig. 1a).

\section{Organic carbon}

We assess OC fluxes within the storage compartments on the basis of information available in the scientific literature. Conservation of mass established in the budget analysis allows us to evaluate how soil erosion and translocation (lateral transfers) have apparently affected the net vertical flux of $\mathrm{C}$ between OC and the atmosphere. We analyzed SOC using the State Soil Geographic Database (STATSGO; U.S. Department of Agriculture 1994). Average organic carbon (OCA) is the average SOC percentage in surface soil horizons, calculated from ranges of organic matter (OM) within each of $\sim 33000$ STATSGO map units (see Appendix).

In order to compare SOC in erosional and depositional soils and estimate the geographic extent of these areas, we identified those soil units in the STATSGO database that could be considered "floodplain" soils, as representative of alluvium. STATSGO does not contain an attribute that directly differentiates between upland and floodplain soils, so we used inundation frequency for this purpose (see Appendix). We assume that upland soils are the sources and that a combination of the floodplain and low terrace soils and water impoundments are depositional areas for eroded SOC. This is an oversimplification, because there will be local depositional areas within the upland soils and erosional areas within the soils designated as floodplains. However, at the regional scale, we feel it is reasonable to think of upland soils as source areas and floodplain and low terrace soils as dominantly depositional. For subsequent comparisons, the data for upland and floodplain SOC were aggregated back to HUC8, and then to subsystem average values.

\section{RESULTS}

\section{Soils across the Mississippi Basin}

Fig. 2 shows the spatial distribution of STATSGO map units that we classified as upland and floodplain soils (including low terraces that flood) across the MS Basin, and illustrates the OCA of these soils. STATSGO data are designed for regional analysis, so the map underestimates the area of alluvial deposits in smaller stream systems. Nevertheless, the analysis is useful for comparison between upland soils and larger floodplain features, and underestimation of area should be small in comparison to the area of large floodplain deposits.

At this scale and resolution, floodplain soils represent $\sim 8 \%$ of the total basin area, but both soils and organic carbon are heterogeneously distributed. Floodplain soils occupy $>50 \%$ of the LMS area, $<1 \%$ of the $\mathrm{AR}$, and $\sim 5 \%$ of the other subsystems. Both the northern reaches of the UMS and the lower portion of the MS delta have soils with $\mathrm{OCA}>4 \%$. No other region- 

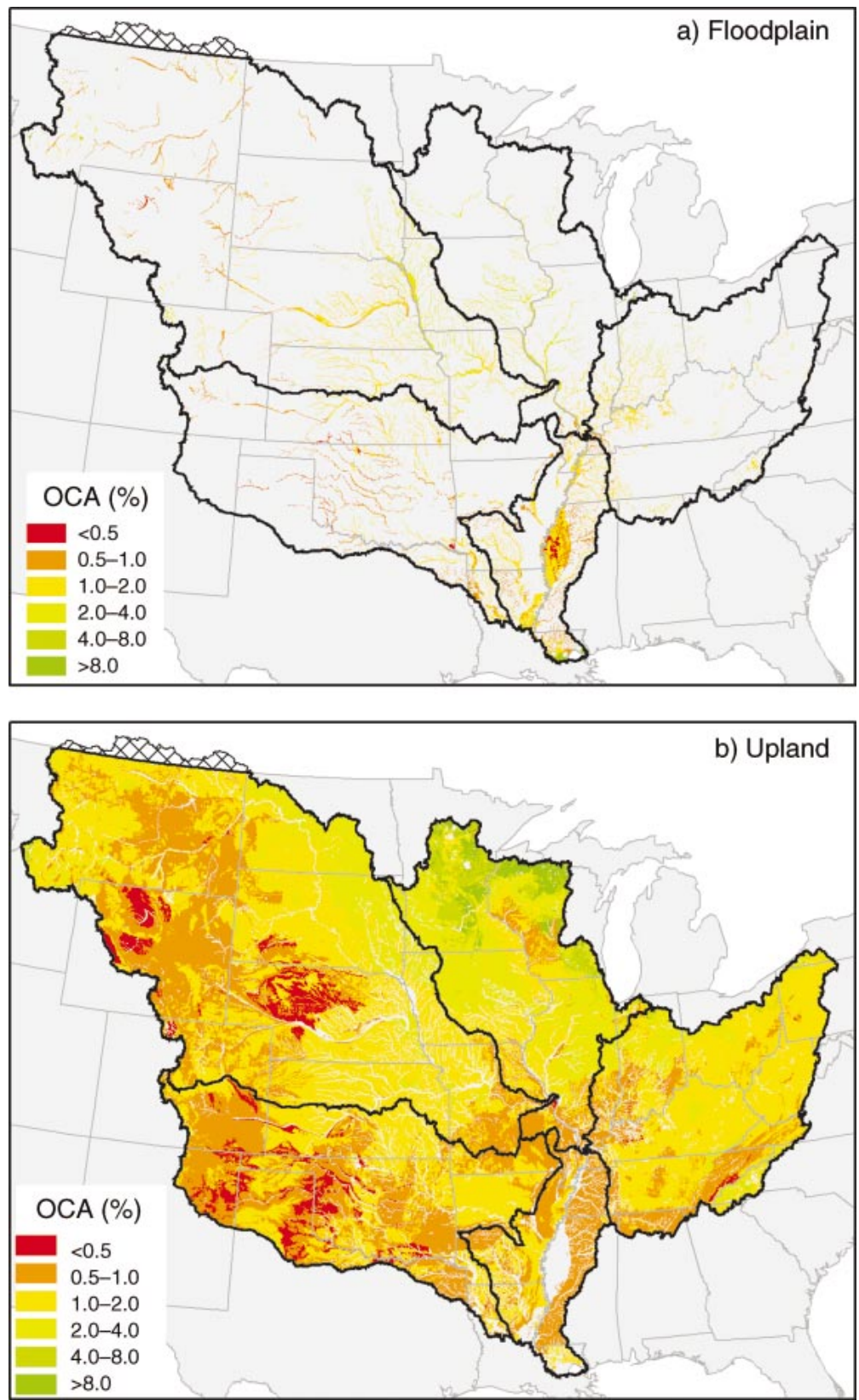

FIG. 2. Average soil organic carbon (OCA) for (a) upland and (b) floodplain soils across the Mississippi Basin, as derived from STATSGO.

ally significant area exceeds $4 \%$, even though individual map units throughout the area show OCA $>4 \%$ when viewed in detail. Widespread areas have OCA $<1 \%$, and the average for the entire Basin is $1.5 \%$.

Because STATSGO is based on modern soil surveys (generally conducted since 1960), properties in its database reflect anthropogenically induced changes in the erosional and depositional phases of map units delineated during this time period. The data used to assign values for properties such as OM have also been affected by land use. That is, the properties in the STATS-
GO database are primarily a function of long-term regional factors (climate, organisms, relief, time), with an overprint of recent $(\sim 150 \mathrm{yr})$ influences by land use.

Floodplain soils would have OCA similar to upland soils from which they were derived if erosion were conservative with respect to SOC. A negative or positive difference between floodplain and upland OCA would indicate the difference between oxidation and sequestration. Floodplain and upland OCA, respectively, at the HUC8 aggregation are $1.52 \pm 0.06$ and 
$1.53 \pm 0.04 \%$ (mean $\pm \mathrm{SE}$; see details in Appendix; floodplain OCA/upland OCA $=0.99 \pm 0.07$ ). These percentages do not differ significantly at the $95 \% \mathrm{CL}$ ( $t$ test). We conclude that upland and associated floodplain soils are indistinguishable with respect to OCA, at the scale of the HUC8s and as an average across the basin.

\section{Erosion of bulk soil and carbon}

In our earlier publication on the fates of eroded materials in the conterminous United States (Smith et al. 2001), we included both wind and water erosion. In the present analysis we exclude wind erosion. Much of the wind-eroded material is apparently redeposited relatively close to its source, and only a small proportion of it appears to leave the continent. Because this redeposition represents dispersal across the landscape, rather than accumulation into localized deposits, it becomes a part of the soil surface. Its subsequent erosion by water would be accounted for in the Universal Soil Loss Equation (USLE) estimates for sheet and rill erosion. Water erosion rates for bulk soil and SOC across the MS Basin are summarized by HUC8 in Fig. 3, and the average ratio of SOC erosion to bulk erosion by subsystem is in Table 2 .

\section{Fates of eroded material}

We next discuss lateral translocations of erosion products in terms of river efflux from the subsystems and within-system deposition in impoundments and alluvium.

River efflux.-Table 3 summarizes river efflux and composition for the five subsystems. Effluxes from the upper subsystems represent erosional influxes entering the rivers within those subsystems, while effluxes from the LMS include both influxes from upstream and erosional influxes originating within the LMS. Flowweighted average concentrations for the gaging stations are listed in Table 3. Although the MO is by far the largest subsystem by area, all subsystems other than the AR have higher river discharges. Even the AR has a higher discharge per unit area. The MO has by far the highest total suspended solids (TSS) concentration, has a higher fraction of its total organic carbon (TOC) as particulate organic carbon (POC) than as dissolved organic carbon (DOC), and has the lowest TOC/TSS ratio. A comparison of Tables 2 and 3 demonstrates that the MO has a TOC/TSS export ratio fairly close to the SOC erosion/total erosion ratio, while the other subsystems have TOC/TSS export ratios substantially exceeding the erosion ratios.

Deposition in water impoundments.-As previously discussed (Smith et al. 2001, 2002; Renwick et al. 2005 , in press), water impoundments cover only 2\% of the landscape area, yet their deposition accounts for $\geq 50 \%$ of bulk erosion products. A surprising conclusion is that small artificial water bodies (primarily farm ponds) occupying only one-fifth of total impoundment area may account for $25-50 \%$ of total impoundment deposition. Even though small impoundments cover a much smaller area, they have much higher deposition rates than the larger water bodies (see also Renwick 1996, 2005). Ritchie (1989) showed that sediments in 58 impoundments across the United States have about the same OC content as the upland soils from which they were derived (impoundment OC/SOC $=0.92 \pm$ $0.22)$.

Alluvial deposition.-We estimated that floodplain soils cover $\sim 8 \%$ of the area of the MS Basin, and that these soils have essentially the same OCA as their upland counterparts. We have no way to evaluate typical alluvial deposition rate in any regionally comprehensive manner, but we assume that alluvial deposition per unit area is substantially higher than in situ soil formation rates (e.g., Schlesinger 1990).

Depositional sites, represented here by impoundments ( $\sim 2 \%$ of the land surface area) and alluvial systems (approximated as floodplain soils; $8 \%$ of the area) thus represent $\sim 10 \%$ of the land surface area and have essentially the same OCA values as the remainder of the area-the erosional sites.

\section{DISCUSSION}

\section{Water budget}

Total river discharge from the basin is estimated to be $769 \times 10^{9} \mathrm{~m}^{3} / \mathrm{yr}$ (Fig. 1c). Discharges for each subsystem represent precipitation minus evapotranspiration $(\mathrm{P}-\mathrm{E})$ that occurs within the region in order to balance the river discharges. Thus $\mathrm{P}-\mathrm{E}$ is shown on the budget sheet as an inferred flux (Fig. 1c). The total discharge from the basin is equivalent to an area-normalized discharge of $23.8 \mathrm{~cm} / \mathrm{yr}$. This is close to the long-term discharge $(22.2 \mathrm{~cm} / \mathrm{yr})$ estimated by Ropelewski and Yarosh (1998) for the "Central United States" (a region roughly equivalent, although not identical, to the MS Basin).

\section{Bulk sediment budget}

Eroded materials move laterally until they are redeposited. The redeposition can occur within the boundaries of the subsystem or beyond those boundaries. The major medium for material transport is water, so the river gaging station near the downstream boundary of each subsystem is the monitoring point for transport beyond the boundaries of that subsystem. Fig. 1c incorporates erosion data (from Fig. 3a) and river flux of suspended material (from Table 3 ) into a bulk sediment budget, with inferred fluxes for the redeposition of erosion products that occur within each subsystem balancing erosion and river efflux. Our estimate for sediment discharge from the MS Basin $\left(161 \times 10^{6} \mathrm{t} /\right.$ $\mathrm{yr})$ is within $4 \%$ of the estimate of $167 \times 10^{6} \mathrm{t} / \mathrm{yr}$ by Turner and Rabalais (2004).

Erosion across the entire basin totals $1523 \times 10^{6} \mathrm{t} /$ $\mathrm{yr}$, while sediment discharge is only $161 \times 10^{6} \mathrm{t} / \mathrm{yr}$. 

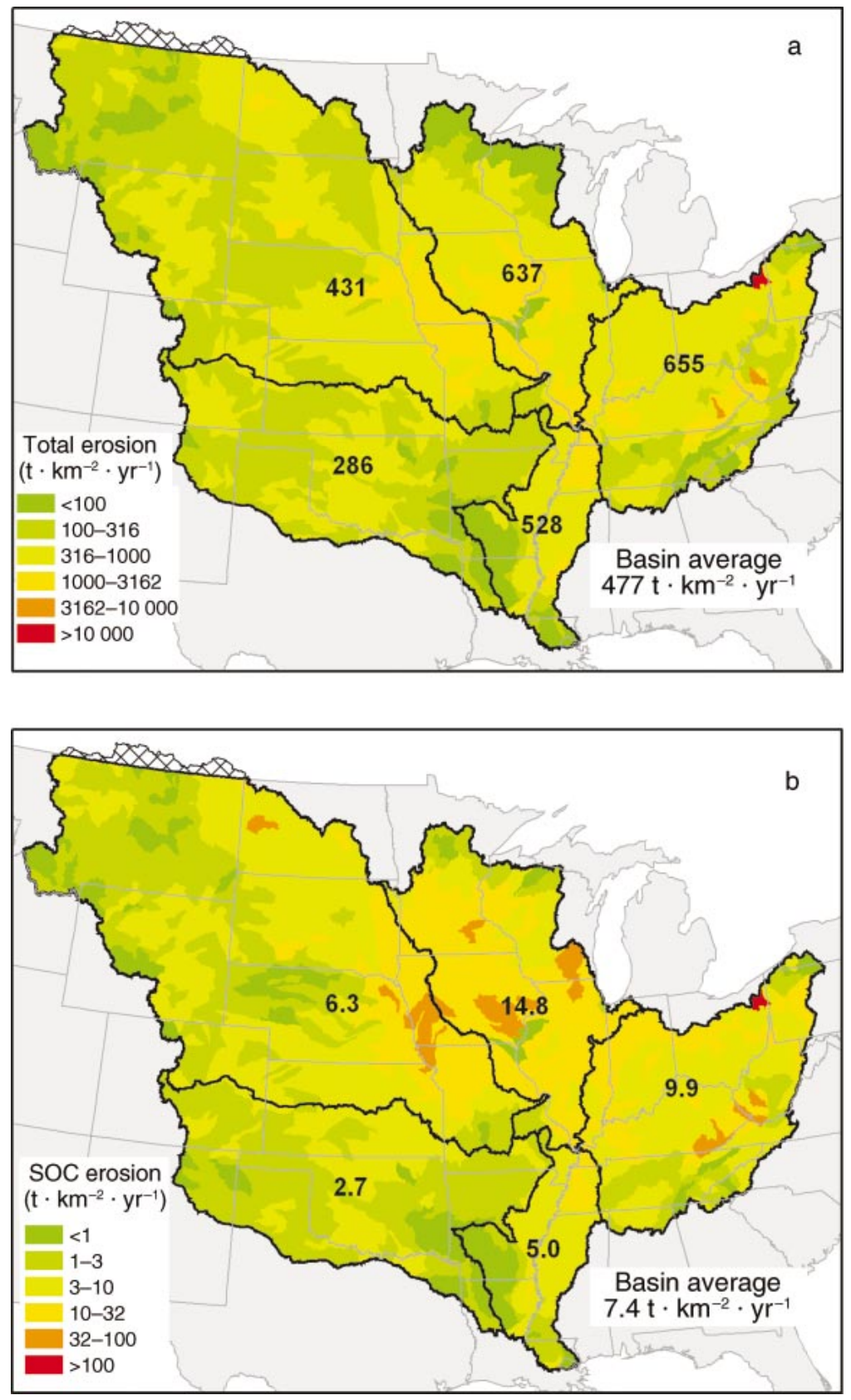

FIG. 3. Water erosion of (a) bulk soil and (b) soil organic carbon across the Mississippi Basin, by HUC8.

TABLE 2. Ratio of soil organic carbon (SOC) erosion by water to total erosion by water, for each subsystem, as averaged from the HUC8s for that subsystem.

\begin{tabular}{lc}
\hline \hline Subsystem & SOC erosion/total erosion \\
\hline AR & 0.0093 \\
MO & 0.0147 \\
UMS & 0.0233 \\
OH & 0.0150 \\
LMS & 0.0095 \\
MS Basin & 0.0155 \\
\hline
\end{tabular}

Notes: Abbreviations used are as in Table 1.
Thus $\sim 90 \%$ of the erosion products must be redeposited within the basin, rather than exported. The retention within the various subsystems lies between 86 and $96 \%$, consistent with the observations that water impoundments and local alluvial deposits are efficient in trapping erosion products in the short term, substantially slowing their downstream translocation on longer time scales (Meade et al. 1990). Processes such as gullying and stream bank erosion contribute significantly to total erosion locally and to an unknown amount at a regional scale. Therefore the discrepancy between 
TABLE 3. Subsystem river water efflux and flow-averaged concentrations, based on data from the gaging stations listed in Appendix Table A1 and illustrated in Fig. 1b.

\begin{tabular}{|c|c|c|c|c|c|c|c|}
\hline Subsystem & $\begin{array}{c}\text { Water } \\
\left(10^{9} \mathrm{~m}^{3} / \mathrm{yr}\right)\end{array}$ & $\begin{array}{l}\text { Total suspended } \\
\text { solids, TSS } \\
\left(\mathrm{g} / \mathrm{m}^{3}\right)\end{array}$ & $\begin{array}{l}\text { Dissolved organic } \\
\text { carbon, DOC } \\
\left(\mathrm{g} / \mathrm{m}^{3}\right)\end{array}$ & $\begin{array}{l}\text { Particulate } \\
\text { organic carbon, } \\
\text { POC }\left(\mathrm{g} / \mathrm{m}^{3}\right)\end{array}$ & $\begin{array}{c}\text { Total } \\
\text { organic carbon, } \\
\text { TOC }\left(\mathrm{g} / \mathrm{m}^{3}\right)\end{array}$ & $\mathrm{POC} / \mathrm{TOC}$ & TOC/TSS \\
\hline AR & 72 & 111 & 4.5 & 1.2 & 5.7 & 0.21 & 0.051 \\
\hline MO & 87 & 905 & 4.8 & 5.6 & 10.4 & 0.54 & 0.012 \\
\hline UMS & 129 & 199 & 6.0 & 3.0 & 9.0 & 0.33 & 0.045 \\
\hline $\mathrm{OH}$ & 266 & 127 & 4.3 & 2.1 & 6.4 & 0.33 & 0.050 \\
\hline LMS & 769 & 210 & 4.0 & 2.0 & 6.0 & 0.33 & 0.029 \\
\hline
\end{tabular}

Notes: Flux values are adjusted from the gaged area to total system areas. Data for the two LMS stations were combined. Abbreviations used are as in Table 1.

erosion and discharge, and consequently the redeposition within the subsystems, is larger than we have estimated. The observation that most bulk erosion products remain within their subsystem of origin is important to our analysis.

\section{Organic carbon budget}

SOC is also detached and relocated by erosion. Some fraction of the eroded SOC redeposits with the bulk sediment. SOC can also be modified by two additional processes: oxidation of old $\mathrm{OC}$ or sequestration of $\mathrm{CO}_{2}$ into new OC. The terms "Ox?" and "Seq?" on Fig. 1a illustrate where these processes might occur.

Fig. 1c summarizes the OC budget. The erosion and river flux data constrain mobilization of SOC and OC export from the subsystems. The sediment budget itself provides an additional part of the OC budget. We have estimated the bulk sediment deposition within each subsystem, and we have demonstrated that the various depositional sites all have about the same proportion of OC as their respective upland soils. Therefore, within each subsystem, we use the SOC/total erosion ratio (Table 2) and the bulk sediment redeposition (Fig. 1c) to estimate OC redeposition. These are direct calculations, rather than values inferred to close the budget.

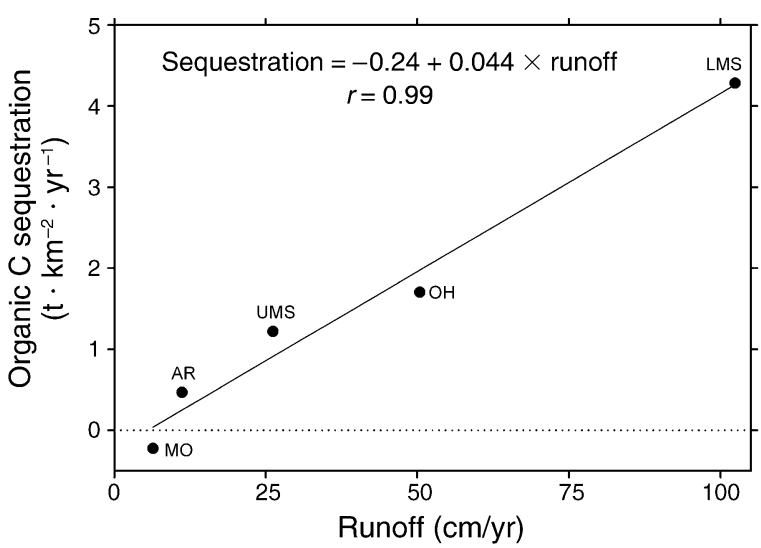

FIG. 4. Model II regression between precipitation minus evaporation (scaled to subsystem area) vs. a similar scaling of net $\mathrm{C}$ sequestration, from Fig. 1c, for the different subsystems.
SOC erosion totals $\sim 23.7 \times 10^{6} \mathrm{t} / \mathrm{yr}(\sim 1.5 \%$ of bulk soil erosion). About $90 \%$ of the eroded SOC is redeposited within the basin (subsystem range $=86-$ $100 \%$ ). However, export of OC from the entire basin is equivalent to $\sim 20 \%$ of SOC erosion, in contrast to $10 \%$ for total sediment export as a fraction of bulk soil erosion. Turner and Rabalais (2004) report OC export from the MS Basin to be $4.5 \times 10^{6} \mathrm{t} / \mathrm{yr}, 7 \%$ lower than our estimate of $4.8 \times 10^{6} \mathrm{t} / \mathrm{yr}$. It is important to note that, as observed for bulk sediment, relatively little of the eroded SOC is exported in the rivers. However, the OC fraction, relative to erosion, exported by rivers is larger than the exported bulk soil fraction.

The OC budget, like the water and bulk sediment budgets, has an inferred balancing term for each subsystem (Fig. 1c). This balancing term is the net of OC sequestration minus oxidation ( $\mathrm{Seq}-\mathrm{Ox}$ ), exchanging with the subsystem boundary on Fig. 1a. Except for the MO, all of these fluxes are positive with respect to the subsystems, implying that the subsystems internally gain $\mathrm{OC}$ in order to balance the budget (total net sequestration $=2.4 \times 10^{6} \mathrm{t} / \mathrm{yr}$ ).

As stated earlier, there is no significant difference in the OC content of upland soils and depositional sites within the subsystems, and the river export of OC in proportion to total sediments is higher than the erosion ratio (contrast Tables 2 and 3). Because of the export imbalance, net sequestration is required in order to maintain the observed equivalence of OC in erosional source areas and depositional sites within the subsystems. This calculation does not identify where, within each subsystem, the net sequestration occurs.

When this estimated sequestration rate is scaled to area and plotted against runoff (Fig. 4), there is a strong correlation between these variables $(r=0.99)$. The observation that runoff is an apparent indicator of $\mathrm{C}$ sequestration in the soils (e.g., Liu 2003) is a direct consequence of the budgets; beyond closing the budgets as we have done, there is no assumption that forced this result. We interpret the net sequestration as a regional budgetary estimate of dynamic replacement (see Stallard 1998, Harden et al. 1999, Liu et al. 2003), with subsystem means between -0.2 and $4.3 \mathrm{t} \cdot \mathrm{km}^{2} \cdot \mathrm{yr}^{-1}$ and a basin mean for $\mathrm{C}$ of $0.7 \mathrm{t} \cdot \mathrm{km}^{2} \cdot \mathrm{yr}^{-1}$. These regional- 
scale replacement rates are low in comparison with modeled field-scale rates for $\mathrm{C}$ (tens of $\mathrm{t} \cdot \mathrm{km}^{-2} \cdot \mathrm{yr}^{-1}$; e.g., Liu et al. 2003); this will vary based on erosion rates, climatic variability, and land use. Precipitation and soil moisture have a strong impact on SOC formation (e.g., Jenny 1941), so sequestration is likely to be limited by precipitation. The large, dry MO subsystem, with a sequestration rate $<0$, dominates the regional value. The wet $\mathrm{OH}$ and LMS subsystems have sequestration rates of $\sim 2$ and $4 \mathrm{t} \cdot \mathrm{km}^{-2} \cdot \mathrm{yr}^{-1}$, respectively.

\section{Uncertainties in the bulk sediment and organic carbon budgets}

The largest obstacle to providing a formal uncertainty analysis of the MS Basin sediment and OC budgets is an uncertain absolute value for erosion. Erosion estimates are based on a large database, so the precision standard error of the estimates can be assumed to be near 0 (Smith et al. 2001). However, the rates are model-based estimates with inherent biases and do not include erosional processes such as gullying and riverbank erosion. Thus the uncertainty in accuracy cannot be formally evaluated regionally. By scaling OC erosion and deposition to bulk soil erosion and deposition, the accuracy uncertainties in bulk erosion and deposition are used to normalize the same uncertainties for OC. From Fig. 1c, redeposition accounts for $\sim 90 \%$ of bulk sediment erosion, and river export accounts for $10 \%$, closely in line with estimates and expectations discussed by Meade et al. (1990).

Estimated OC:bulk sediment ratios for eroded soil, redeposited sediments, and river efflux are 0.015 , 0.015 , and 0.030 , respectively, based on the OC composition of eroded soil, and on compositional comparisons between upland soils and reservoir sediments, upland and floodplain soil composition, and river fluxes. We estimate that the errors on these composition ratios are $<10 \%$, regardless of uncertainties on the fluxes. Most eroded soil redeposited within the basin has an OC content close to the OCA of the upland soil from which it was derived, while the OC:sediment export ratio is about twice the OCA of the eroded soil. This is based on the assumption that floodplain soils and impoundment sediments are derived from eroded upland soils within the same HUC8 or impoundment catchment.

\section{Rates of oxidation in flooded or alluvial environments}

The budget as constructed does not address the question of whether the translocated soil, once redeposited, reacts differently than it did in its original state as uneroded upland soil. For this evaluation we turn to the scientific literature.

Primary production occurs in lakes and other freshwater bodies, and various authors have considered the role of this production as a possible sink for atmospheric $\mathrm{CO}_{2}$ (Mulholland and Elwood 1982, Ritchie
1989, Dean and Gorham 1998, Stallard 1998). However, any net sink or source would be represented by the difference between primary production and respiration, not by primary production alone. Recent considerations have addressed the possibility that the net characteristic of freshwater bodies might be $\mathrm{CO}_{2}$ release rather than uptake (Cole et al. 1994, St. Louis et al. 2000). St. Louis et al. (2000) stated that the net C release rate from temperate water impoundments is about $140 \mathrm{t} \cdot \mathrm{km}^{-2} \cdot \mathrm{yr}^{-1}$. Their "temperate sites" are largely in Wisconsin and British Columbia. These authors reported higher fluxes for tropical sites $(\sim 350$ $\left.\mathrm{t} \cdot \mathrm{km}^{-2} \cdot \mathrm{yr}^{-1}\right)$. We suspect that many of the MS Basin impoundments experience a release rate that is higher than the higher latitude sites of that study, so we use an intermediate value of $250 \mathrm{t} \cdot \mathrm{km}^{-2} \cdot \mathrm{yr}^{-1}$ for net $\mathrm{CO}_{2}$ emissions from water bodies in the MS Basin.

Richey et al. (2002) estimated $\mathrm{CO}_{2}$ emission rates for the rivers and wetlands of the Amazon basin to be about $120 \mathrm{t} \cdot \mathrm{km}^{-2} \cdot \mathrm{yr}^{-1}$, and Cole and Caraco (2001) estimated emissions from the Hudson river system as $\sim 200 \mathrm{t} \cdot \mathrm{km}^{-2} \cdot \mathrm{yr}^{-1}$. These are the closest we have found to estimates for emission from alluvial areas and rivers. These rates for one large tropical river system (including wetlands and river) and one moderately large temperate river system are in the lower part of the range of estimated emission rates for impoundments. Because these data are both limited and within the scatter of impoundment rates, we assign a nominal net $\mathrm{CO}_{2}$ emission rate of $<250 \mathrm{t} \cdot \mathrm{km}^{-2} \cdot \mathrm{yr}^{-1}$ to all depositional sites (alluvial soils and impoundments).

Water bodies and alluvial soils are clearly $\mathrm{CO}_{2}$ sources, but these sources must be compared to the locations from which the decomposing $\mathrm{OC}$ came. In the absence of SOC erosion, primary production minus respiration in impoundments should equal or exceed 0 , so the material driving net $\mathrm{OC}$ decomposition must come from a terrestrial source, ultimately erosion. The question relevant to this study is neither "Are the depositional sites $\mathrm{CO}_{2}$ sources or not?" nor "Is there oxidation of soil organic carbon deposited in sediment in water bodies and alluvial deposits?" but rather "How does the $\mathrm{CO}_{2}$ flux of depositional sites compare with the flux for the same material before it was displaced from upland soils into the depositional sites?"

Global soil respiration totals $\sim 60-70 \times 10^{9} \mathrm{t} / \mathrm{yr}$ (Raich and Schlesinger 1992, Schimel 1995). This respiration is in approximate balance with terrestrial primary production. If this respiration primarily occurs over an area of about $100 \times 10^{6} \mathrm{~km}^{2}$ (that is, about two-thirds of the global land area, leaving out polar regions and extreme deserts), it is equivalent to an average respiration of $\sim 650 \mathrm{t} \cdot \mathrm{km}^{-2} \cdot \mathrm{yr}^{-1}$. Using the equations of Raich and Schlesinger (1992), the estimated flux derived for the average conditions in the subsystems of the MS Basin (Table 1) is $\sim 500 \pm 40$ $\mathrm{t} \cdot \mathrm{km}^{-2} \cdot \mathrm{yr}^{-1}$, a value within $\sim 25 \%$ of the global average and twice the estimated emission rate per unit area for 
depositional sites. Both the upland soil respiration rate and net respiration in depositional sites can be considered background rates that have been perturbed by some unknown extent by accelerated erosion. Because SOC erosion $\left(\sim 7 \mathrm{t} \cdot \mathrm{km}^{-2} \cdot \mathrm{yr}^{-1}\right.$ across the MS Basin $)$ is equivalent to $<4 \% / \mathrm{yr}$ of upland soil respiration, we assume that this perturbation of background respiration is also small.

Alluvial soils and freshwater impoundments across the MS Basin cover $\sim 10 \%$ of the terrestrial area, so net oxidation of $\mathrm{OC}$ derived from upland soil erosion and delivered to these depositional sites is estimated to account for $10 \% \times(<250 / 500)$, or $<5 \%$ of the oxidation rate that this same material would have undergone as upland soils. This regionally integrated rate of oxidation in depositional sites is dominated by the differences in total area between upland soils and depositional sites, with probable differences in emission rates per unit area being of secondary importance. Assigning the small loss of upland SOC to export and redeposition vs. elevated in situ oxidation would be difficult to isolate experimentally. Our interpretation of export to depositional sites and consequent diminution of oxidation is consistent, however, with process-based arguments and models based on the effects of water content on SOC oxidation (Rice 2002, Liu et al. 2003, Hanson et al. 2004).

From Fig. 1c, it can be seen that an amount of OC equivalent to $\sim 90 \%$ of the SOC eroded across the MS Basin is subsequently redeposited within the basin $\left(\sim 21 \times 10^{6} \mathrm{t} / \mathrm{yr}\right.$, out of a total erosion of $\sim 24 \times 10^{6}$ $\mathrm{t} / \mathrm{yr}$ ). The deposition sites include alluvium and freshwater bodies; colluvial deposition is of unknown importance but assumed to behave similarly to these other depositional modes. The eroded organic matter was part of the SOC, which was respiring at an average rate of about $500 \mathrm{t} \cdot \mathrm{km}^{-2} \cdot \mathrm{yr}^{-1}$. The combined effect of moving the material from the landscape as a whole to much smaller depositional areas in which respiration per unit area is somewhat diminished results in a substantially decreased total decomposition rate. This is also consistent with the discussion by Liu et al. (2003), of widespread vs. concentrated deposition scenarios. Our analysis suggests that, integrated across the landscape, eroded material is respiring at a rate $<5 \%$ of the oxidation rate that this same material would have experienced as upland soil, so this erosion and redeposition causes an effective net sink of $\sim 21 \times 10^{6} \mathrm{t} / \mathrm{yr}(7$ $\left.\mathrm{t} \cdot \mathrm{km}^{-2} \cdot \mathrm{yr}^{-1}\right)$. This "passive" depositional sink for $\mathrm{CO}_{2}-$ $\mathrm{C}$ is in addition to the active net $\mathrm{CO}_{2}$ sequestration sink (or dynamic replacement) of $2 \times 10^{6} \mathrm{t} / \mathrm{yr} \quad(0.6$ $\mathrm{t} \cdot \mathrm{km}^{-2} \cdot \mathrm{yr}^{-1}$ ) inferred to balance OC erosion and translocation (net sequestration, or dynamic replacement; Figs. 1c, 4).

\section{CONCLUSIONS}

Agriculturally induced soil erosion in the MS Basin accelerates soil degradation by removal of OM from upland soils (occupying 90\% of the landscape) and relocation to depositional sites $(10 \%)$, rather than by net loss of OM to oxidation. The "spatial appearance" of relocating SOC from the landscape as a whole to a dramatically smaller area is a lower value for areaaveraged SOC. The total mass of OC across the landscape remains approximately constant; the redistributed OC has a lower spatially integrated oxidation rate; and the areas with erosionally diminished SOC are sites of $\mathrm{OC}$ regrowth. The $\mathrm{OC}$ erosion and relocation are significant agricultural issues because they lower the area and fertility of arable lands, but diminished fertility of arable lands does not, per se, constitute a net loss of SOC from the global soil bank to atmospheric $\mathrm{CO}_{2}$. In addition, of course, there is a net $\mathrm{OC}$ river export in excess of bulk sediment export.

The conventional view of the $\mathrm{C}$-cycle consequences of soil erosion is that at least $20 \%$ of the eroded SOC is oxidized (Lal 2003). This widely used but poorly supported assumption would predict that the MS Basin soil erosion (with a basin average SOC erosion rate of $7.4 \mathrm{t} \cdot \mathrm{km}^{-2} \cdot \mathrm{yr}^{-1}$ across the $3.6 \times 10^{6} \mathrm{~km}^{2}$ of the MS Basin) results in a loss of at least $1.5 \mathrm{t} \cdot \mathrm{km}^{-2} \cdot \mathrm{yr}^{-1}$ of OC to atmospheric $\mathrm{CO}_{2}$. Instead, our budgetary calculations show that four of the five subsystems apparently exhibit a net sequestration of $\mathrm{CO}_{2}$ into $\mathrm{OC}$, with an overall total of about $7 \mathrm{t} \cdot \mathrm{km}^{-2} \cdot \mathrm{yr}^{-1}$. This amounts to a net difference of $>8 \mathrm{t} \mathrm{C} \cdot \mathrm{km}^{-2} \cdot \mathrm{yr}^{-1}$, with respect to $\mathrm{CO}_{2}$ release vs. sequestration between the " $>20 \%$ oxidation" conceptual model for OC loss and the budgetary evidence for both slowed oxidation and uptake of $\mathrm{CO}_{2}$ into SOC. In short, for the region studied, soil erosion results in or contributes to a net sink for atmospheric $\mathrm{CO}_{2}$, not a net source.

If this conclusion holds for other regions, it has major implications for balancing the global $\mathrm{C}$ budget. We have previously suggested (Smith et al. 2001, Renwick et al. 2004) that eroded SOC undergoes little oxidation, and that the apparently incorrect assumption that it does oxidize represents a fallacious source that could account for up to about $1 \mathrm{Gt} / \mathrm{yr}$ of the "missing sink" for atmospheric $\mathrm{CO}_{2}$ globally. The present results not only confirm this earlier estimate but also increase the estimated size of the sink by finding evidence for net uptake rather than simply reduced emission. Data from other environments are needed to scale up this study of the MS Basin quantitatively, but based on the original estimates of Smith et al. (2001), we now suggest that our initially estimated sink strength is likely to be low.

We believe this is a realistic regional appraisal of a temperate climate region that has been the site of intense agricultural activity for more than 100 years. Over most of this period, the land use has represented "modern agricultural practices" for the time. This analysis, like others (e.g., Stallard 1998, Liu et al. 2003), suggests the need for reconsideration of the role of soil OC erosion and redeposition in global carbon 
budgets. The budgetary approach used here can be used both in other regions of the globe and in more detailed (local) analysis within regions to provide an objective assessment of the fates of eroded SOC.

\section{ACKNOWLEDGMENTS}

This paper is part of ongoing studies by the coauthors to determine the role of landscape erosion and deposition in material fluxes and biogeochemical cycling. Parts of this work have been supported by internal institutional support at CICESE, Emporia State University, Miami University College of Arts and Science, and the Kansas Geological Survey, and by a Kansas NASA EPSCoR grant awarded to R. W. Buddemeier and R. O. Sleezer. We thank the numerous individuals who contributed technical assistance or conceptual support to these efforts. Three reviewers have provided useful critical comments on versions of this manuscript. Of these, we would like to single out Jon Cole, who thoroughly grasped the big picture of what we were advancing and whose summary comment seems worth quoting: "The idea that soil erosion is a large net sink of atmospheric $\mathrm{CO}_{2}$ is very interesting, well supported by the arguments and data in this paper, and likely to be a huge controversy. This controversy is a good thing, as Martha Stewart might say."

\section{Literature Cited}

Aguilar, R., and R. D. Heil. 1988. Soil organic carbon, nitrogen, and phosphorus quantities in northern Great Plains rangeland. Soil Science Society of America Journal 52: 1076-1081.

Amundson, R. 2001. The carbon budget in soils. Annual Review of Earth and Planetary Sciences 29:535-562.

Bajracharya, R. M., R. Lal, and J. M. Kimble. 2000. Diurnal and seasonal $\mathrm{CO}_{2}-\mathrm{C}$ flux from soil as related to erosion phases in central Ohio. Soil Science Society of America Journal 64:286-293.

Bohn, H. L. 1982. Estimate of organic carbon in world soils: II. Soil Science Society of America Proceedings 46:11181119.

Brubaker, S. C., A. J. Jones, D. T. Lewis, and K. Frank. 1993. Soil properties associated with landscape position. Soil Science Society of America Journal 57:235-239.

Church, M., and O. Slaymaker. 1989. Disequilibrium of Holocene sediment yield in glaciated British Columbia. Nature 337:452-454.

Cole, J. J., and N. F. Caraco. 2001. Carbon in catchments: connecting terrestrial carbon losses with aquatic metabolism. Marine and Freshwater Research 52:101-110.

Cole, J. J., N. F. Caraco, G. W. Kling, and T. K. Kratz. 1994. Carbon dioxide supersaturation in the surface waters of lakes. Science 265:1568-1570.

Dean, W. E., and E. Gorham. 1998. Magnitude and significance of carbon burial in lakes, reservoirs, and peatlands. Geology 26:535-538.

Dearing, J. A., and R. T. Jones. 2003. Coupling temporal and spatial dimensions of global sediment flux through lake and marine sediment records. Global and Planetary Change 39: $147-168$.

Eswaran, H., E. Van Den Berg, and P. Reich. 1993. Organic carbon in soils of the world. Soil Science Society of America Journal 57:192-194.

Hanson, P. C., A. I. Pollard, D. L. Bade, K. Predick, S. R. Carpenter, and J. A. Foley. 2004. A model of carbon evasion and sedimentation in temperate lakes. Global Change Biology 10:1285-1298.

Harden, J. W., J. M. Sharpe, W. J. Parton, D. S. Ojima, T. L. Fries, T. G. Huntington, and S. M. Dabney. 1999. Dynamic replacement and loss of soil carbon on eroding cropland. Global Biogeochemical Cycles 13:885-901.
Jenny, H. 1941. Factors of soil formation. McGraw-Hill, New York, New York, USA.

Jobbagy, E. G., and R. B. Jackson. 2000. The vertical distribution of soil organic carbon and its relation to climate and vegetation. Ecological Applications 10:423-432.

Kleiss, H. J. 1970. Hillslope sedimentation and soil formation in northeastern Iowa. Soil Science Society of America Proceedings 34:287-290.

Lal, R. 1995. Global soil erosion by water and carbon dynamics. Pages 131-142 in R. Lal, J. Kimble, E. Levine, and B. A. Stewart, editors. Soils and global change. CRC Press, Boca Raton, Florida, USA.

Lal, R. 2003. Soil erosion and the global carbon budget. Environment International 29:437-450.

Lal, R. 2004. Soil carbon sequestration impacts on global climate change and food security. Science 304:1623-1627.

Lal, R., M. Griffin, J. Apt, L. Lave, and M. G. Morgan. 2004. Managing soil carbon. Science 304:393.

Liu, S., N. Bliss, E. Sundquist, and T. G. Huntington. 2003. Modeling carbon dynamics in vegetation and soil under the impact of soil erosion and deposition. Global Biogeochemical Cycles 17:1074/doi:10.1029/2002GB002010〉

Martel, Y. A., and E. A. Paul. 1974. The use of radiocarbon dating of organic matter in the study of soil genesis. Soil Science Society of America Proceedings 38:501-506.

Meade, R. H., T. R. Yuzyk, and T. J. Day. 1990. Movement and storage of sediment in rivers of the United States and Canada. Pages 255-280 in M. G. Wolman and H. C. Riggs, editors. Surface water hydrology, geology of North America. Volume O-1. Geological Society of America, Boulder, Colorado, USA.

Milliman, J. D., and J. P. M. Syvitski. 1992. Geomorphic/ tectonic control of sediment discharge to the ocean: the importance of small mountainous rivers. Journal of Geology 100:525-544.

Mulholland, P. J., and J. W. Elwood. 1982. The role of lake and reservoir sediments as sinks in the perturbed global carbon cycle. Tellus 34:490-499.

Phillips, J. D. 1991. Fluvial sediment budgets in the North Carolina piedmont. Geomorphology 4:231-241.

Post, W. M., R. C. Izaurralde, L. K. Mann, and N. Bliss. 2001. Monitoring and verifying changes of organic carbon in soil. Climate Change 51:73-99.

Raich, J. W., and W. H. Schlesinger. 1992. The global carbon dioxide flux in soil respiration and its relationship to vegetation and climate. Tellus 44B:81-99.

Raymond, P. A., and J. E. Bauer. 2001. Riverine export of aged terrestrial organic matter to the North Atlantic Ocean. Nature 409:497-500.

Renwick, W. H. 1996. Continental-scale reservoir sedimentation patterns in the United States. Pages 513-522 in D. E. Walling and B. W. Webb, editors. Erosion and sediment yield: global and regional perspectives. International Association of Hydrological Sciences Publication 236. University of Exeter, Wallingford, UK.

Renwick, W. H., K. J. Carlson, and J. K. Hayes-Bonham. 2005. Trends in recent reservoir sedimentation rates in southwestern Ohio. Journal of Soil and Water Conservation 60:72-79.

Renwick, W. H., S. V. Smith, J. D. Bartley, and R. W. Buddemeier. 2005. The role of impoundments in the sediment budget of the conterminous United States. Geomorphology, in press.

Renwick, W. H., S. V. Smith, R. O. Sleezer, and R. W. Buddemeier. 2004. Comment on "Managing Soil Carbon" (II). Science 305:1567c.

Rice, C. W. 2002. Storing carbon in soil: why and how? Geotimes 47:14-17.

Richey, J. C., J. M. Melack, A. K. Aufdenkampe, V. M. Ballister, and L. L. Hess. 2002. Outgassing from Amazonian 
rivers and wetlands as a large tropical source of atmospheric $\mathrm{CO}_{2}$. Nature 416:617-620.

Ritchie, J. C. 1989. Carbon content of sediments of small reservoirs. Water Resources Bulletin 25:301-308.

Ropelewski, C. F., and E. S. Yarosh. 1998. The observed mean annual cycle of moisture budgets over the Central United States (1973-92). Journal of Climate 11:21802189.

Rosenzweig, C., and D. Hillel. 2000. Soils and global climate change: challenges and opportunities. Soil Science 165:4755.

Schimel, D. S. 1995. Terrestrial ecosystems and the carbon cycle. Global Change Biology 1:77-91.

Schlesinger, W. H. 1990. Evidence from chronosequence studies for a low carbon-storage potential of soils. Nature 348:232-234.

Schlesinger, W. H. 1995. Soil respiration and changes in soil carbon stocks. Pages 159-168 in G. M. Woodwell and F. T. Mackenzie, editors. Biotic feedbacks in the global climatic system: will the warming feed the warming? Oxford Press, New York, New York, USA.

Smith, S. V., W. H. Renwick, J. D. Bartley, and R. W. Buddemeier. 2002. Distribution and significance of small, artificial water bodies across the United States landscape. Science of the Total Environment 299:21-36.

Smith, S. V., W. H. Renwick, R. W. Buddemeier, and C. J. Crossland. 2001. Budgets of soil erosion and deposition for sediments and sedimentary organic carbon across the conterminous United States. Global Biogeochemical Cycles 15:697-707.

Soil Survey Division Staff. 1999. Soil taxonomy. Second edition. USDA-NRCS Agricultural Handbook 436. U.S. Government Printing Office, Washington, D. C., USA.
Stallard, R. F. 1998. Terrestrial sedimentation and the carbon cycle: coupling weathering and erosion to the carbon cycle. Global Biogeochemical Cycles. 12:231-257.

St. Louis, V. L., C. A. Kelly, E. Duchemin, J. W. M. Rudd, and D. W. Rosenberg. 2000. Reservoir surfaces as a source of greenhouse gases to the atmosphere: a global estimate. BioScience 50:766-775.

Swift, R. S. 2001. Sequestration of carbon by soil. Soil Science 166:858-871.

Syvitski, J. P. M., and M. D. Moorehead. 1999. Estimating river-sediment discharge to the ocean: application to the Eel margin, northern California. Marine Geology 154:1328.

Trimble, S. W. 1983. A sediment budget for Coon Creek, the Driftless Area, Wisconsin, 1853-1977. American Journal of Science 283:454-474.

Turner, R. E., and N. N. Rabalais. 2004. Suspended sediment, C, N, P, and Si yields from the Mississippi River Basin. Hydrobiologia 511:79-89.

Uri, N. D. 2001. The potential impact of conservation practices in US agriculture on global climate change. Journal of Sustainable Agriculture 18:109-131.

U.S. Department of Agriculture. 1994. State soil geographic (STATSGO) data base. Miscellaneous Publication 1492. Natural Resources Conservation Service, National Soil Survey Center, Fort Worth, Texas, USA.

Van Oost, K., G. Govers, T. A. Quine, and G. Heckrath. 2004. Comment on "Managing Soil Carbon" (I). Science 305 $1567 \mathrm{~b}$.

Yonker, C. M., D. S. Schimel, E. Paroussis, and R. D. Heil. 1988. Patterns of organic carbon accumulation in a semiarid shortgrass steppe, Colorado. Soil Science Society of America Journal 52:478-483.

\section{APPENDIX}

Details of materials and methods used are available in ESA's Electronic Data Archive: Ecological Archives A015-057-A1. 